\title{
Research on the forecasting strategy of early aftershocks in North China
}

\author{
Jinmeng $\mathrm{Bi}^{1}$, Changsheng Jiang*,2 \\ (1) Tianjin Earthquake Agency, Tianjin, China \\ (2) Institute of Geophysics, China Earthquake Administration, Beijing, China
}

Article history: received October 30, 2019; accepted February 26, 2020

\begin{abstract}
To systematically investigate short-term aftershock forecasts following moderate-to-strong earthquakes of North China so as to develop "operational" aftershock forecasting strategies tailored to regional seismic characteristics, we adopt the widely used Reseanberg-Jones (R-J) model and the Omi-R-J model to explore aftershock forecasting strategies of 24 earthquake sequences of North China, and use the $\mathrm{N}$-test and T-test to evaluate the forecasting effectiveness. Early forecast results after mainshock show that the R-J model and the Omi-R-J model have an average effectiveness rate of $77.0 \%$ and $87.9 \%$ for the selected sequences, respectively. The R-J model has a lower ratio of forecasting "too low" numbers of earthquakes while the Omi-R-J has a rather low overall "failure rate". With the rapid development of monitoring network after 2008, the efficacy of earthquake sequence forecasting has improved significantly, with monitoring capability being an important factor constraining forecasting effectiveness. The possible scientific strategies for the aftershocks forecasting in North China include strengthening the construction of seismic networks and applying better algorithms for detecting or simulating aftershocks, giving priority to using the Omi-R-J model within a short period of time (within 2 hours) after the mainshock, and weigh the range of the actual number of future aftershocks by appling the R-J model and the Omi-R-J model simultaneously.
\end{abstract}

Keywords: Reseanberg-Jones model, Omi-R-J model, Aftershock probability forecasting, Effectiveness evaluation.

\section{Introduction}

It is crucial to release the reliable and authoritative aftershock forecast information in time for earthquake tracking, relief, emergency management, and order maintenance in disaster areas after a moderate-to-strong earthquake [Reasenberg and Jones, 1989; Gerstenberger et al., 2005; Marzocchi and Lombardi, 2009; Woessner et al., 2011; Nanjo et al., 2012; Ogata et al., 2013]. Moderate-to-strong earthquakes can cause great losses to life and property, which is in no small portion due to secondary disasters including aftershocks especially within three days after the mainshock, while the occurrence time of larger aftershocks varies from a few days to several months after the mainshock, and may even be as close as within one day after [Japan Meteorological Agency (JMA), 2009]. In the early stage after the mainshock, the drowning effect of the large surface wave amplitude of the mainshock and the superposition of signals from a large number of simultaneous aftershocks will reduce the seismic monitoring 


\section{Jinmeng Bi et al.}

capacity in the region and even globally within several hours after the mainshock, presenting significant challenges for aftershock probability forecasting [Ogata, 1983; Utsu et al., 1995; Enescu et al., 2007; Iwata, 2008]. Therefore, the research on the scientific strategy of the aftershock forecasting in the early stage after mainshock is a realistic problem in a general sense.

In the current Collaboratory for the Study of Earthquake Predictability (CSEP) program, the short-term aftershock forecasting model has seen rapid development [Schorlemmer et al., 2018]. More than 400 earthquake forecast models have been submitted to the four international testing centers of the CSEP program for "retrospective" and "prospective" research, [Jiang et al., 2015, 2017, 2018; Omi et al., 2015; 2016; Bi and Jiang, 2017; Han et al., 2017; Taroni et al., 2018; Ogata et al., 2018]. The Operational Aftershock Forecasting (OAF) conducted by the US Geological Survey (USGS) and the Global Earthquake Model (GEM) project represents an important application in earthquake forecasting strategies [Helmstetter et al., 2006; Console et al., 2010].

City clusters of North China are developing rapidly, and the coordinated development of the Beijing-TianjinHebei region and the construction of Xiong'an New Area are well underway. To ensure the smooth implementation of national strategies, it is necessary to upgrade security measures, such as seismic hazard assessment, which includes aftershock probability forecasting, as well as risk reduction. It is important to rely on modern technology at home and abroad, and mature regional applications and innovative research to effectively improve the technical capabilities of aftershock forecasting and risk management decisions. Technically, by testing in North China the internationally accepted and comparable R-J model [Reasenberg and Jones, 1989] and the Omi-R-J model [Omi et al., 2013, 2015, 2016] capable of using incomplete seismic records, we hope to derive knowledge about the suitability of these two aftershock forecasting models, in a bid to inform aftershock forecasting strategies of North China for the benefit of actual earthquake disaster prevention and relief work.

\section{Data and Method}

Distributed across the North China region $\left(34 \sim 43^{\circ} \mathrm{N}, 10 \sim^{2} 125^{\circ} \mathrm{E}\right)$ are complex seismic belts such as the Zhangiiakou-Bohai, the Hebei plain, the Shanxi, and the Tanlu seismic belts, featuring strong tectonic activity, the development of faults and folds, various types of earthquake sequences, and frequent occurrence of seismic events, causing great losses to people's lives and property. The region is prone to strong earthquakes, with historical data indicating more than 20 earthquakes of magnitude 7 or above. The 1976 Tangshan Earthquake in particular is the deadliest earthquake in the $20^{\text {th }}$ century, destroying the entire city and left 242,000 people dead and 164,000 seriously injured.

For the study on the aftershock sequences of moderate-to-strong earthquakes in North China, we adopted the "National Unified Official Catalogue"1 provided by the China Earthquake Networks Center. We use Gardner-knopoff method [Gardner and Knopoff, 1974] to separate 10145 earthquake catalogues with completeness magnitude of 3.0 and above in North China. After deleting the aftershocks, we obtained 2629 earthquake catalogues, 159 of which are above 4.5. In order to select the earthquake sequence, we use the method of the "natural boundary method" [Bi and Jiang, 2017, 2019] based on the combination of latitude-time plot, longitude-time plot and epicenter distribution map to select desired sequences. In addition, according to the calculation requirements of R-J model, a certain amount of aftershock events are needed in the earthquake sequence. Therefore, in the process of preliminary selection of earthquake sequence, we need not less than 60 earthquake events, and not less than 30 earthquake events above the completeness magnitude for parameter fitting.

In the fitting process of the R-J model, to ensure the completeness of earthquake catalogs and the inclusion of a sufficient number of aftershocks in the calculation, we also use the "Magnitude-Rank" method [Huang, 2006; Jiang and Wu, 2011; Zhuang et al., 2012] to choose completeness magnitude of different sequence. The "MagnitudeRank" method is based on the sequence of earthquake occurrence time, and then the completeness magnitude is determined according to the distribution of magnitude and rank. In addition, in the process of parameter fitting, it is necessary to set the starting time of fitting $C_{0}$, which is related to the cutoff magnitude $M_{\mathrm{c}}$ : the larger $M_{\mathrm{c}}$, the smaller $C_{0}$. By adjusting the relationship between the two parameters, we find out the values of $M_{\mathrm{c}}$ and $C_{0}$ suitable for each seismic sequence, so as to ensure that enough earthquakes participate in the fitting and calculation.

\footnotetext{
${ }^{1}$ National Earthquake Cataloging System, http://10.5.160.18/console/exit.action, accessed November 22, 2018.
} 


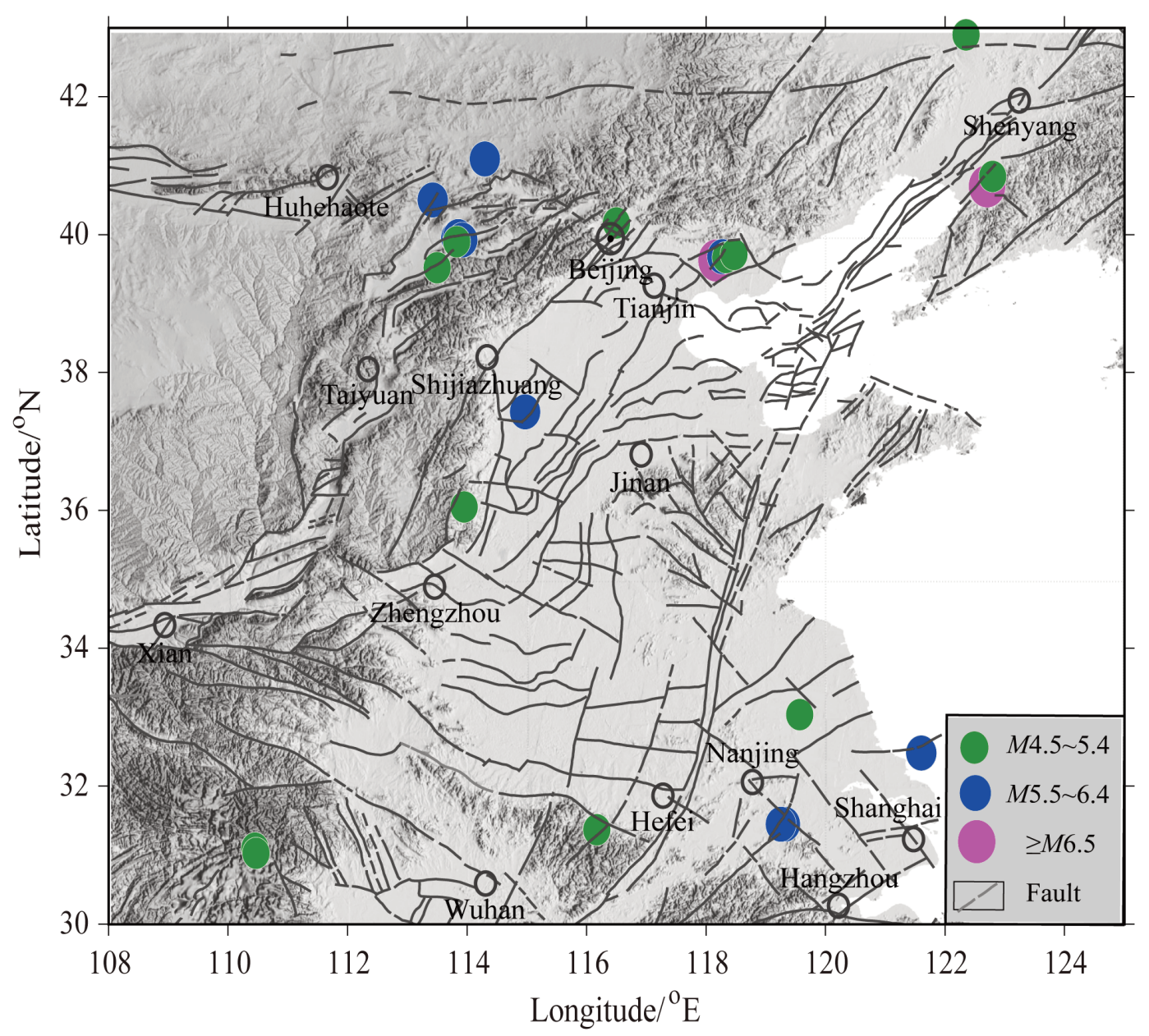

Figure 1. Seismicity distribution of 24 earthquake sequences in North China.

According to the above selection rules, a total of 24 earthquake sequences in North China are selected, and their spatial distribution map is shown in Figure 1, and their mainshock parameters are shown in Table 1, together with the values of $M_{\mathrm{c}}$ and $C_{0}$. Taking the $M_{\mathrm{S}} 5.6$ Fengzhen earthquake in Inner Mongolia on August 13, 1981 as an example, Figure 2 gives a schematic diagram for the selection of this sequence. Iterating each seismic event step by step, the Omi-R-J method can obtain seismic detection rate changes over time during the study period. Figure 3 shows the distribution of the $50 \%$ seismic detection rate $\mu(t)$ of the $M_{\mathcal{S}} 5.6$ Fengzhen earthquake in Inner Mongolia according to Ogata and Katsura (1993)'s model. To investigate the stability of the fitting process, detection rate distributions in 5 periods, namely, $0 \sim 0.10$ days, $0 \sim 1.00$ days, $0 \sim 3.00$ days, $0 \sim 5.00$ days, and $0 \sim 30.00$ days after the mainshock, were separately investigated.

Reasenberg and Jones [1989] developed the Reseanberg-Jones (R-J) model based on the "Omori-Utsu" formula [Omori, 1894; Utsu, 1961] as the intensity constraint and the G-R law [Gutenberg and Richter, 1944; Aki, 1965] as the frequency constraint for short-term forecasts of aftershocks. Therefore, the function of aftershock intensity whose magnitude is at or above $M$ at time $t$ in the earthquake sequence can be written as:

$$
\lambda(t, M)=10^{a_{\mathrm{OML}}+\mathrm{b}_{\mathrm{OML}}\left(M_{\mathrm{c}}-M\right)}\left(t+c_{\mathrm{OML}}\right)^{-p_{\mathrm{OML}}}
$$

In order to overcome the shortcomings of not fully utilizing a large number of small-magnitude earthquake events below the $M_{\mathrm{c}}$, and inability to quickly and reliably estimate model parameters in the early stage of aftershock sequences, Omi et al. [2013] developed the "Omi-R-J model" which is based on the R-J model but incorporates some new technologies. Omi et al. [2013] used the expression of the detection rate function $q(M)$ provided by Ogata and Katsura $[1993,2006]$ to describe detection degrees of the incomplete parts of seismic records. 
Jinmeng Bi et al.
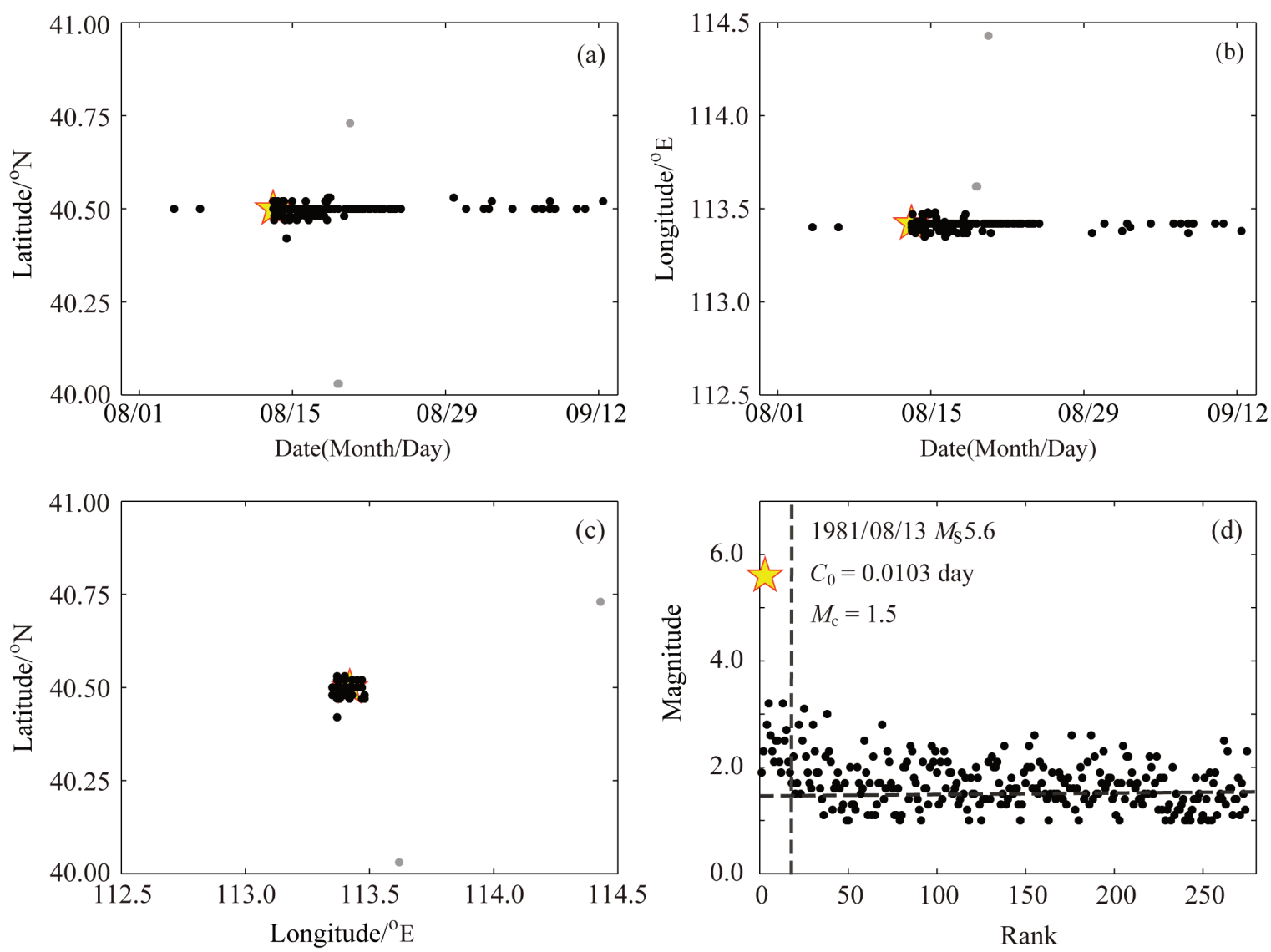

Figure 2. Selection of 13 August 1981 Fengzhen, Inner Mongolia, $M_{\mathrm{S}} 5.6$ earthquake sequence. (a) Latitude-time plot; (b) Longitude-time plot; (c) Epicenter distribution plot; (d) Magnitude-Rank plot. The yellow stars represent the mainshock and the black dots represent events in the selected earthquake sequence, the gray ones represents "background earthquake" in the earthquake sequence. The horizontal dashed line indicates the cutoff magnitude, $M_{\mathrm{c}}$, while the vertical dashed line indicates the starting time of model fitting, $C_{0}$.

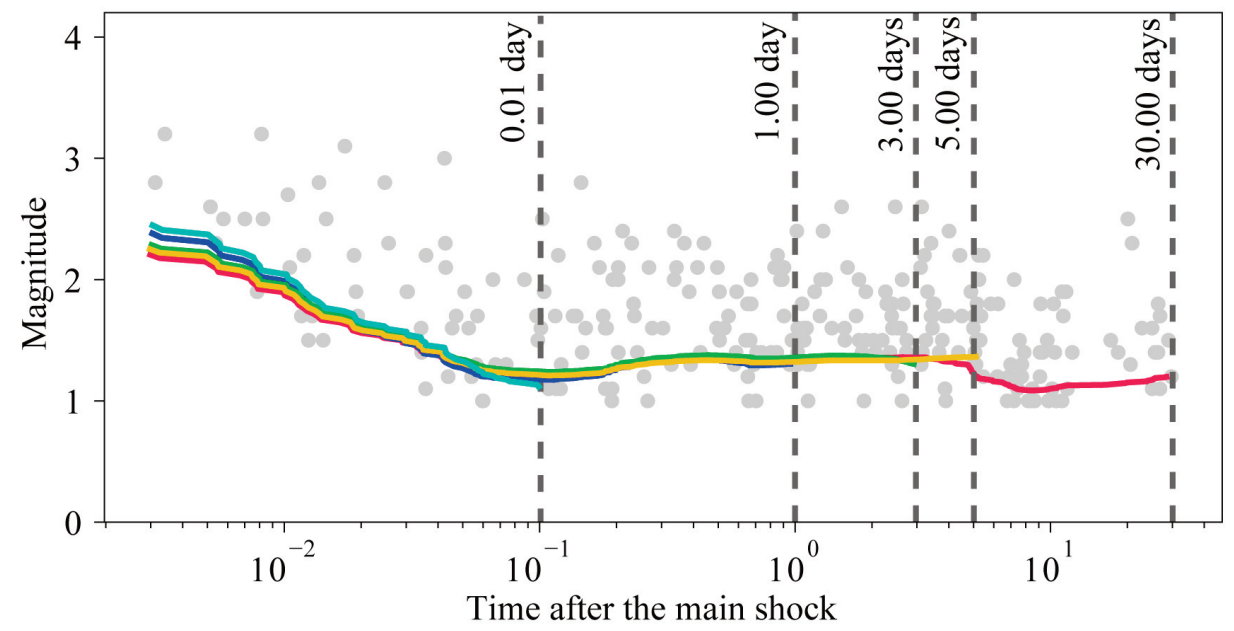

Figure 3. Catalogue completeness analysis of the Fengzhen $M_{\mathrm{S}} 5.6$ earthquake aftershock sequence in Inner Mongolia on August 13, 1981. The colored curves indicate the results of the $50 \%$ detection rate calculated from data at different time periods ( $0 \sim 0.10$ days, $0 \sim 1.00$ days, $0 \sim 3.00$ days, $0 \sim 5.00$ days and $0 \sim 30.00$ days) after the mainshock. 
Forecasting strategy of early aftershocks

\begin{tabular}{|c|c|c|c|c|c|c|c|c|}
\hline $\mathbf{S} / \mathbf{N}$ & Date & Time & Mag. & Long. & Lat. & $M_{\mathrm{c}}$ & $C_{0}$ & Code \\
\hline 1 & 1973/03/11 & $16: 40: 08$ & 4.9 & 116.170 & 31.370 & 1.5 & 0.0078 & A \\
\hline 2 & $1974 / 04 / 22$ & 08:29:19 & 5.5 & 119.320 & 31.450 & 1.2 & 0.0603 & B \\
\hline 3 & $1975 / 02 / 04$ & $19: 36: 04$ & 7.3 & 122.700 & 40.700 & 4.0 & 0.1119 & $\mathrm{C}$ \\
\hline 4 & $1976 / 07 / 28$ & $03: 42: 53$ & 7.8 & 118.180 & 39.630 & 4.0 & 0.0132 & $\mathrm{D}$ \\
\hline 5 & 1979/07/09 & $18: 57: 23$ & 6.0 & 119.250 & 31.450 & 1.5 & 0.0050 & E \\
\hline 6 & 1980/08/02 & 03:10:42 & 5.1 & 113.950 & 36.050 & 1.3 & 0.0313 & F \\
\hline 7 & $1981 / 08 / 13$ & $11: 01: 57$ & 5.6 & 113.420 & 40.500 & 1.5 & 0.0103 & G \\
\hline 8 & 1981/11/09 & 02:01:04 & 5.8 & 114.970 & 37.430 & 2.4 & 0.0062 & $\mathrm{H}$ \\
\hline 9 & $1984 / 05 / 21$ & $23: 38: 54$ & 6.2 & 121.600 & 32.480 & 2.4 & 0.0084 & I \\
\hline 10 & $1989 / 10 / 19$ & $01: 01: 34$ & 5.8 & 113.820 & 39.950 & 3.0 & 0.0288 & $\mathrm{~J}$ \\
\hline 11 & $1991 / 03 / 26$ & 02:02:38 & 5.8 & 113.850 & 39.970 & 1.2 & 0.0144 & $\mathrm{~K}$ \\
\hline 12 & $1991 / 05 / 30$ & $07: 05: 55$ & 5.6 & 118.270 & 39.680 & 2.4 & 0.0086 & $\mathrm{~L}$ \\
\hline 13 & $1995 / 10 / 06$ & $06: 26: 53$ & 5.4 & 118.330 & 39.670 & 1.6 & 0.0066 & $\mathrm{M}$ \\
\hline 14 & $1996 / 12 / 16$ & $05: 36: 33$ & 4.5 & 116.500 & 40.170 & 1.2 & 0.2191 & $\mathrm{~N}$ \\
\hline 15 & $1998 / 01 / 10$ & $11: 50: 39$ & 6.3 & 114.300 & 41.100 & 2.2 & 0.0134 & $\mathrm{O}$ \\
\hline 16 & $1999 / 05 / 15$ & $16: 11: 17$ & 4.6 & 113.500 & 39.520 & 1.3 & 0.0024 & $\mathrm{P}$ \\
\hline 17 & 1999/11/01 & $21: 25: 13$ & 5.6 & 113.920 & 39.920 & 2.3 & 0.0180 & Q \\
\hline 18 & $2008 / 11 / 14$ & $06: 53: 28$ & 4.7 & 122.794 & 40.842 & 1.5 & 0.5454 & $\mathrm{R}$ \\
\hline 19 & $2010 / 04 / 04$ & $21: 46: 45$ & 4.6 & 113.830 & 39.900 & 1.2 & 0.0018 & S \\
\hline 20 & $2012 / 05 / 28$ & $10: 22: 52$ & 4.7 & 118.470 & 39.710 & 1.1 & 0.0029 & $\mathrm{~T}$ \\
\hline 21 & $2012 / 07 / 20$ & $20: 11: 51$ & 4.9 & 119.570 & 33.040 & 1.5 & 0.0580 & $\mathrm{U}$ \\
\hline 22 & $2013 / 04 / 22$ & $17: 11: 52$ & 5.3 & 122.350 & 42.900 & 2.0 & 0.0617 & $\mathrm{~V}$ \\
\hline 23 & $2013 / 12 / 16$ & $13: 04: 52$ & 5.1 & 110.450 & 31.100 & 1.4 & 0.0181 & $\mathrm{~W}$ \\
\hline 24 & 2018/10/11 & $15: 06: 31$ & 4.5 & 110.470 & 31.030 & 1.4 & 0.3498 & $\mathrm{X}$ \\
\hline
\end{tabular}

Table 1. Mainshock parameters for the 24 selected earthquake sequences in North China

The actually recorded probability density function can be written as:

$$
P(M \mid \beta, \mu, \sigma)=\frac{e^{-\beta M} q(M \mid \mu, \sigma)}{\int_{-\infty}^{+\infty} e^{-\beta M} q(M \mid \mu, \sigma) d M}=\frac{e^{-\beta M} q(M \mid \mu, \sigma)}{e^{\left(-\beta M+\beta^{2} \sigma^{2} / 2\right)} / \beta}=\beta e^{-\beta(M-\mu)+\beta^{2} \sigma^{2} / 2} q(M \mid \mu, \sigma)
$$

After obtaining parameters $\beta, \sigma$ and $V$ and the dynamic changesof detection rate by the "state-space" model, where $V$ is a hyper-parameter that controls the degree of smoothness of $\mu(t)$. The parameters $p_{\mathrm{ORJ}}, c_{\mathrm{ORJ}}$ and $k_{\mathrm{ORJ}}$ from the Omori-Utsu (O-U) formula for aftershock decay and the parameter $\beta$ from the Gutenberg-Richter (G-R) formula for the magnitude-frequency relation $(\beta=b \ln 10)$ are constants to be estimated. Thereafter, the number of forecasting aftershocks in the magnitude range $M>M_{c}$ and any time interval $\left[t_{2}, t_{\mathrm{e}}\right]$ can be calculated using equation (1):

$$
N=\int_{t_{2}}^{t_{e}} \int_{M_{c}}^{\infty} \lambda(t, M) d t d M
$$




\section{Jinmeng Bi et al.}

\section{Fitting of Sequence Parameters}

It is essential to obtain stable model sequence parameters before investigating corresponding strategies for aftershock probability forecasting [Jiang et al., 2017, 2018; Bi and Jiang, 2017]. For the parameters $K_{\mathrm{OML}}, c_{\mathrm{OML}}$ and $p_{\text {OML }}$ of the R-J model, we can use the maximum likelihood method to fit the Omori-Utsu formula, and use the Fisher information matrix to estimate the standard deviation of these parameters [Ogata, 1983]. The parameter $b$-value and its standard deviation can be calculated using the maximum likelihood method [Aki, 1965] and the methods given by Shi and Bolt [1982], respectively.

In order to study the continuous change of the R-J model parameters, we used a series of time windows with fixed starting points but increasing length to select earthquake sequences and perform model parameter fitting. The setting of the starting time $C_{0}$ and the ending time (sequence duration time or starting time of forecasting) $t_{2}$ of these time windows is shown in Tables 1 and 2, respectively. Among them, $t_{2}$ generally increases gradually from 0.05 day after the mainshock to 5.00 days in steps of 0.05 day, but in order to ensure that the time windows contain a sufficient number of earthquakes, the forecast starting point of $t_{2}$ for each earthquake sequence is slightly different, see Table 2. Taking the Zhangbei $M_{\mathrm{S}} 6.3$ earthquake in Hebei Province on January 10, 1998 as an example, Figure 4(a1), (b1), (c1), (d1) provide the values of $p_{\text {ОмL }}, c_{\text {ОМL }}, K_{\text {ОмL }}$ and $b_{\text {OML }}$ obtained by fitting these parameters versus sequence duration, which indicates relatively sharp changes in the early stage of the sequence but gradual stabilization in later stages.
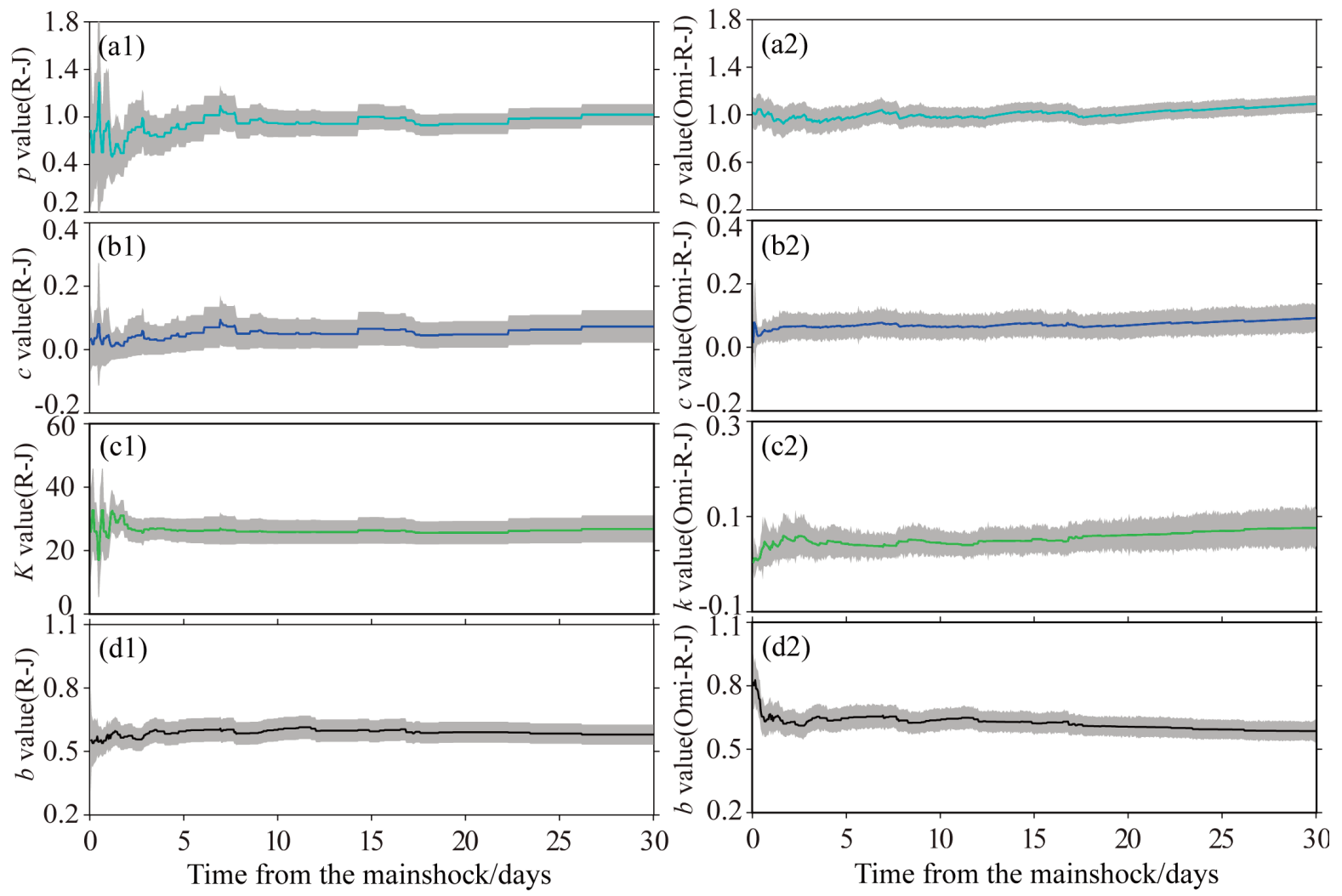

Figure 4. Parameters of R-J model and Omi-R-J model against the duration time (since the mainshock occurred) in fitting the Zhangbei $M_{S} 6.3$ earthquake in Hebei Province on January 10, 1998. (a1) (d1) represent R-J model parameters $p_{\mathrm{OML}}, c_{\mathrm{OML}}, K_{\mathrm{OML}}$ and $b_{\mathrm{OML}}$ respectively; (a2) (d2) represent Omi-R-J model parameters $p_{\mathrm{ORJ}}, c_{\mathrm{ORJ}}, k_{\mathrm{ORJ}}$ and $b_{\mathrm{ORJ}}$ respectively. The cut-off magnitude is set as $M_{\mathrm{C}}=M_{\mathrm{L}} 2.5$ in model fitting, the starting time is $C_{0}=0.0134$ day and the ending time in the fitting process (sequence duration) increasing from 0.05 day to 30.00 days at the time step of 0.05 day. The gray area shows the range of the standard deviations of the parameters shown in each subgraph. 
The parameters of the Omi-R-J model were fitted using Bayesian estimates given by Omi et al. [2013]. Specifically, the Newton's iteration and the expectation maximum (EM) algorithm were used to optimize the hyperparameters $\beta, \sigma, V$ and $\mu(t)$, respectively, while the maximum likelihood method is used to estimate the parameters $p_{\mathrm{ORJ}}, c_{\mathrm{ORJ}}$, and $k_{\mathrm{ORJ}}$. Different from the traditional R-J method, the Omi-R-J method utilizes all aftershock events recorded after the earthquake, and performs parameter fitting immediately (within 2 hours) after the earthquake, requiring only a small number of aftershock events to obtain seismic sequence parameters. Taking the Zhangbei $M_{\mathrm{S}} 6.3$ earthquake in Hebei Province on January 10, 1998 as an example, we fitted the model parameters, and selected three time periods with relatively sharp changes in the early stage, namely, $0 \sim 0.10$ days, $0 \sim 1.00$ days, $0 \sim 2.00$ days (Figure 5). As Figure 5 shows, the model parameters at early sequence duration $t_{2}=0.10$ day after the mainshock were $\beta_{\mathrm{ORJ}}=1.838 \pm 0.244, k_{\mathrm{ORJ}}=0.014 \pm 0.044, p_{\mathrm{ORJ}}=1.006 \pm 0.133, c_{\mathrm{ORJ}}=0.080 \pm 0.094$; the model parameters at sequence duration $t_{2}=1.00$ day were $\beta_{\mathrm{ORJ}}=1.476 \pm 0.170, k_{\mathrm{ORJ}}=0.039 \pm 0.038, p_{\mathrm{ORJ}}=1.008 \pm 0.115, c_{\mathrm{ORJ}}=0.052 \pm 0.031$; the model parameters at sequence duration $t_{2}=2.00$ days were $\beta_{\mathrm{ORJ}}=1.440 \pm 0.136, k_{\mathrm{ORJ}}=0.052 \pm 0.045, p_{\mathrm{ORJ}}=$ $0.975 \pm 0.123, c_{\mathrm{ORJ}}=0.066 \pm 0.044$, where $\beta_{\mathrm{ORJ}}$ value was obtained by $\beta_{\mathrm{ORJ}}=\ln (10) \times b_{\mathrm{ORJ}}$.

For the Omi-R-J model, the parameters were fitted as close as possible to the start of the earthquake. In the 0.05 days after the mainshock, only the Liyang $M_{\mathrm{S}} 5.5$ earthquake in Jiangsu on April 22, 1974, and the Shunyi $M_{\mathrm{S}} 4.5$ earthquake in Beijing on December 16, 1991 have only one aftershock in their sequences 0.05 day after the mainshock, with simulation starting from 0.10 day and 0.15 day after the earthquake respectively, while the starting times of the other 22 events were all set to begin from 0.05 day. Same as the R-J model, the simulation time increases at a time step of 0.05 day in multiple time periods to 30 days. Figure $4(\mathrm{a} 2)$, (b2), (c2), (d2) provide the values of $p_{\mathrm{ORJ}}$, $c_{\mathrm{ORJ}}, k_{\mathrm{ORJ}}$ and $b_{\mathrm{ORJ}}$ of the Zhangbei $M_{\mathrm{S}} 6.3$ earthquake in Hebei Province on January 10, 1998 versus sequence duration. Compared with the R-J model parameters, Omi-R-J model parameters in the early stage manifest smoother changes.

\section{Statistical test of forecast results}

We used the N-test [Kagan and Jackson, 1995; Schorlemmer et al., 2007; Zechar, 2010] as adopted in CSEP for earthquake number verification to determine the deviation of the forecasting number of earthquakes by the R-J model and the Omi-R-J model from the actual number of earthquakes. We use $N_{\text {fore }}$ to represent the number of forecasted aftershocks and $N_{\text {obs }}$ to represent the actual number of aftershocks. In the simplified processing of zechar (2010), the "too low" and "too high" in the actual number of aftershocks $N_{\text {obs }}$ is tested by the scores $\delta_{1}$ and $\delta_{2}$, respectively.

$$
\begin{gathered}
\delta_{1}=1-F\left(\left(N_{o b s}-1\right) \mid N_{\text {fore }}\right) \\
\delta_{2}=F\left(N_{o b s} \mid N_{\text {fore }}\right)
\end{gathered}
$$

The effective significance level $\alpha_{\text {eff }}=0.025$ was used to unilaterally test the $\mathrm{N}$-test results. $\delta_{1}<\alpha_{\text {eff }}$ indicates "too low" numbers of forecasted aftershocks, while $\delta_{2}<\alpha_{\text {eff }}$ indicates "too high" numbers of forecasted aftershocks.

As an example, Figure 5(d), (e) and (f) show the forecasts at three "turning points" by the Omi-R-J model for $0.10 \sim 1.10$ days, 1.00 2.00 days, and 2.00 3.00 days after the earthquake. As can be seen, the number of actual earthquakes in the three time periods fall within the $95 \%$ confidence interval of the forecasts, indicating relatively high forecasting efficacy. As an example, we provide the test results of the forecasting efficacy of the R-J and OmiR-J models in predicting the future 1-day aftershock probability of Zhangbei $M_{S} 6.3$ earthquake in Hebei Province on January 10, 1998 with sequence duration time $t_{2}=2.00$ (Figure 6). Figure 6(a), (c) and (b), (d) respectively show the test score $\delta_{1}$ and $\delta_{2}$ of $\mathrm{N}$-test for aftershock occurrence rate forecasting of the two models, indicating relatively good forecasting efficacy in this time period, with the test results of the Omi-R-J model being significantly better than that of the R-J model.

The R-J and Omi-R-J models require a certain number of events for aftershock forecasts due to data quality constraints and other factors for each earthquake sequence. To systematically evaluate the forecasting efficacy for early aftershocks (within 5.00 days after mainshock) of earthquake sequences of North China since 1970, we performed sliding forecasts in multiple time slips (Tables 2 and 3) starting as close as possible to the occurrence time 


\section{Jinmeng Bi et al.}

of earthquake within 0.05 5.00 days, and conducted "quantitative" efficacy evaluation of forecast results as shown in Tables 2 and 3. The corresponding N-test results of the two models are shown in Figure 7, where the red color blocks represent the results when $\delta_{1}<0.025$ and $\delta_{2}<0.025$, the slash time period represents the time period that cannot participate in the calculation because of insufficient data, and the blank area indicates that no earthquake event of or above the cut-off magnitude has occurred in the forecasting period. As the N-test cannot be performed if no actual events have taken place, to ensure objective evaluations, this paper does not include situations with zero actual occurrence despite a forecasted probability of earthquakes.
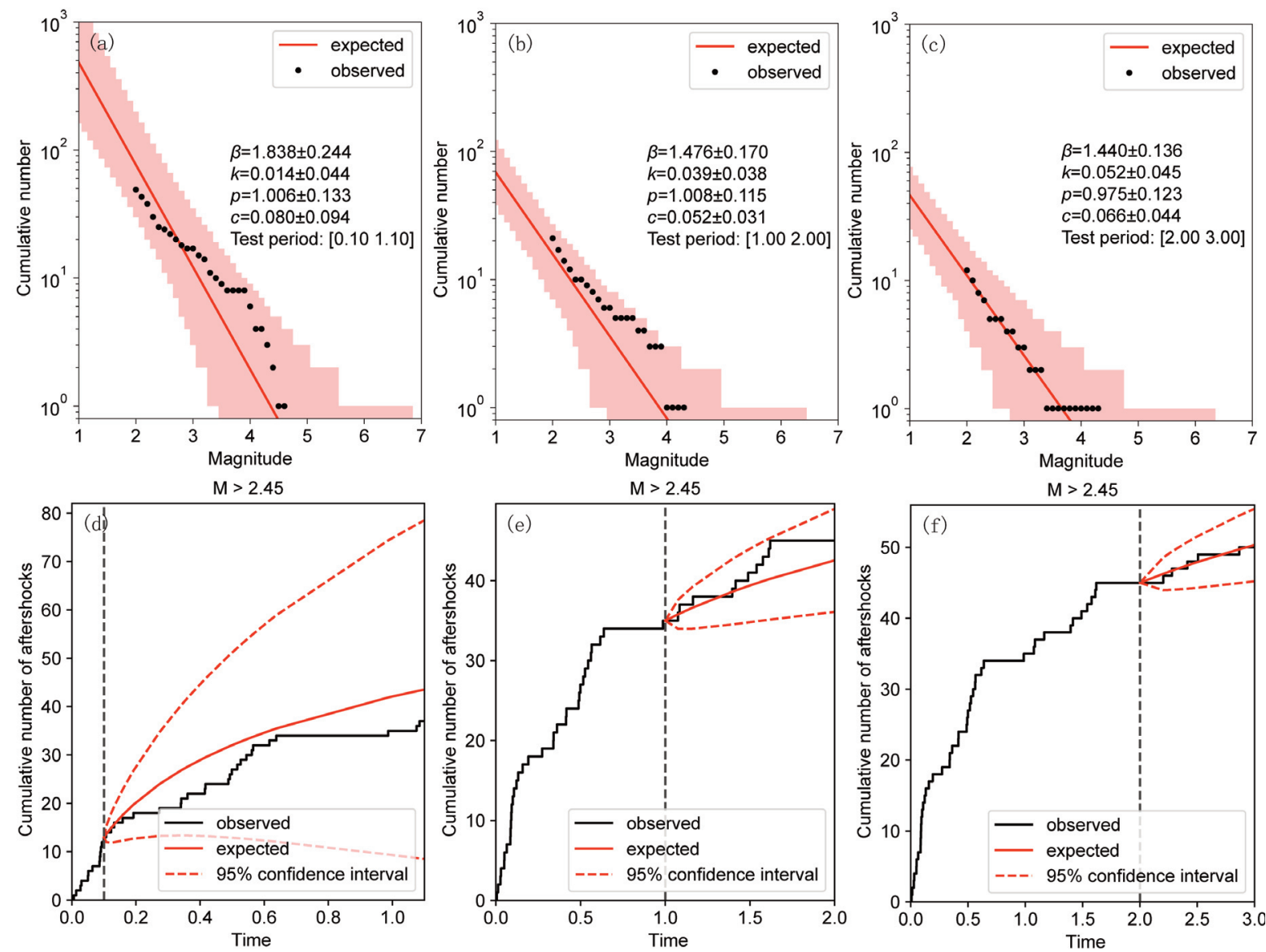

Figure 5. Future 1-day aftershock forecasting for the Zhangbei $M_{\mathrm{S}} 6.3$ earthquake sequence using the Omi-R-J model in Hebei Province on January 10, 1998. Plots (a), (b) and (c) show the comparison of magnitude-cumulative frequency between forecasts (red lines) and actually observed aftershocks (black dots), and their 95\% confidence interval (pink area). Subplots (d), (e), and (f) show the cumulative forecasting values (red curves) and actual observed values (black curves) when $M>2.45$ and at the $95 \%$ confidence interval (red dashed lines). The starting times of forecasts is marked by a black vertical dashed lines, and the ending times is the right edge of the picture. Three plots in each line refer to the different test periods $(0.1,1.1),(1,2)$ and $(2,3)$, respectively.

For complex earthquake sequences, forecasting “failures” were observed even with the well-accepted R-J model and Omi-R-J model. As Table 2, Table 3 and Figure 7 suggest, in all time periods involved in the calculation, the RJ model is more effective than the Omi-R-J model with respect to having "too low" numbers of forecasted events, while the Omi-R-J model considerably outperforms the R-J model in respect to having “too high" numbers of forecasted events. The Omi-R-J model also shows considerably better outcomes in terms of overall failure rates.

As the fitting and calculation of the R-J model is impossible in the early stage of certain sequences, and given relatively poor results of early stage forecasts in statistical test, the actual forecasting efficacy of the R-J model may 

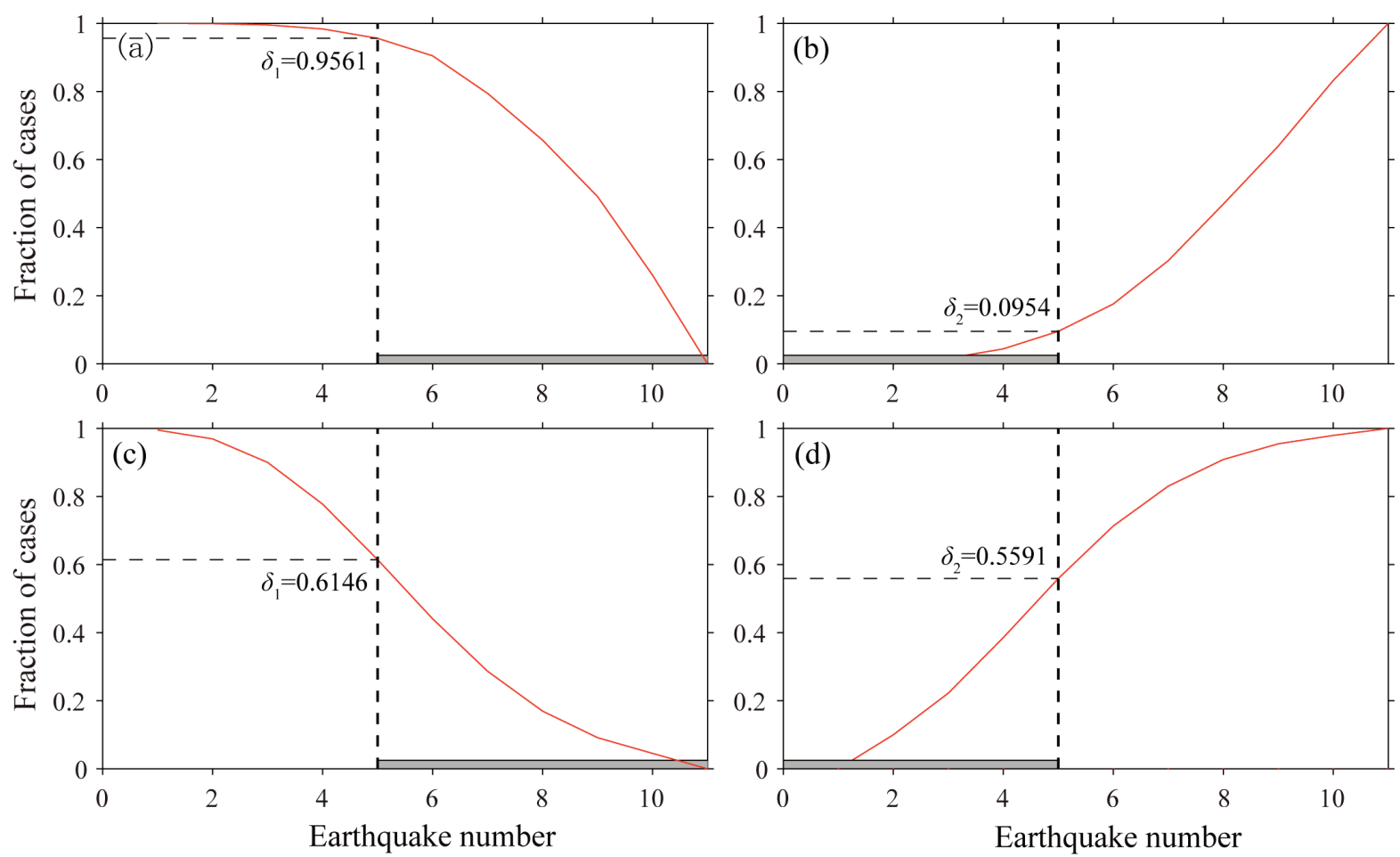

Figure 6. N-test for the short-term forecasting results of the Zhangbei $M_{\mathrm{S}} 6.3$ earthquake sequence, in Hebei Province on January 10, 1998. (a) $\delta_{1}$ results of the N-test for future 1-day forecasting of R-J model; (b) $\delta_{2}$ results of the N-test for future 1-day forecasting of R-J model; (c) $\delta_{1}$ results of the N-test for future 1-day forecasting of Omi-R-J model; (d) $\delta_{2}$ results of the N-test for future 1-day forecasting of Omi-R-J model. All of the above results show the situations when $t_{2}=2.00$ days, $M_{\mathrm{C}}=M_{\mathrm{L}} 2.5$.
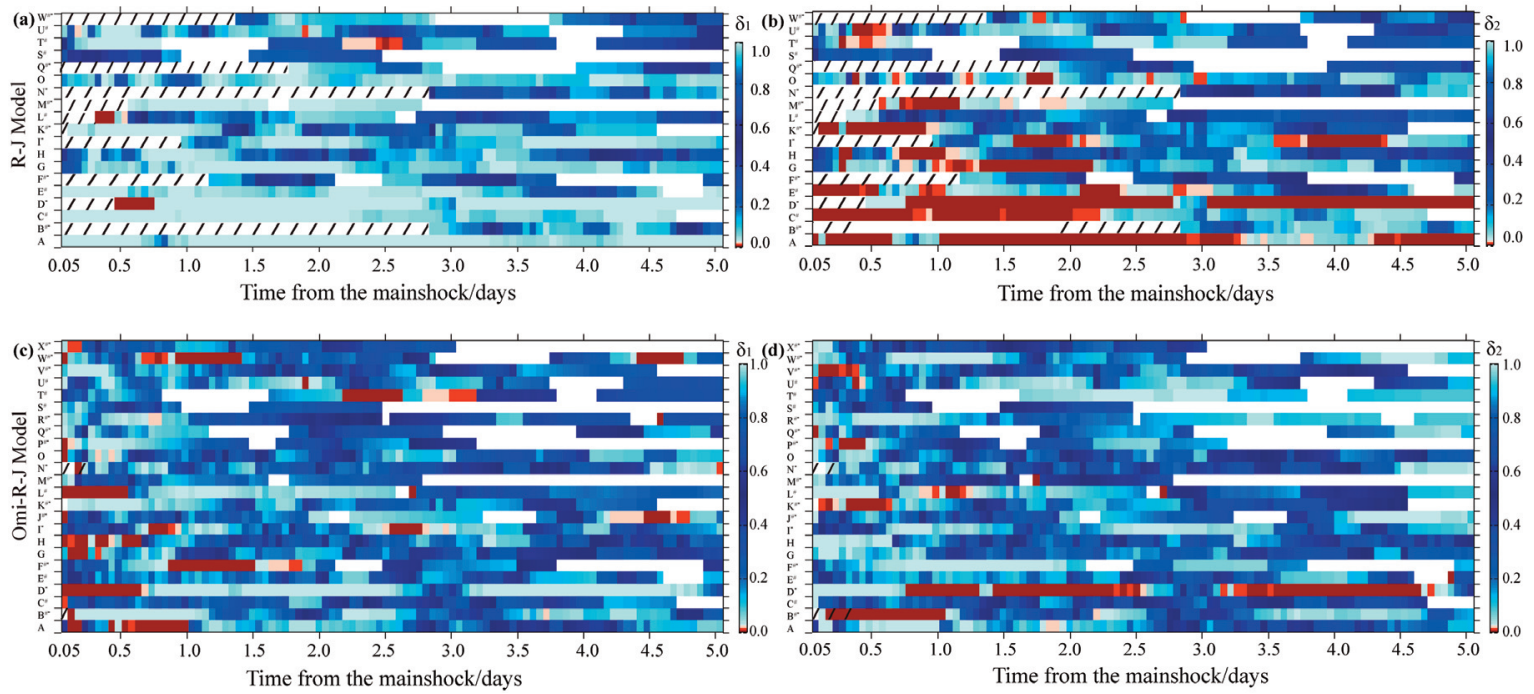

Figure 7. N-test results for the two models for future 1-day aftershock forecasting of the earthquake sequence of North China. (a) $\delta_{1}$-score of R-J model. (b) $\delta_{2}$-score of R-J model. (c) $\delta_{1}$-score of Omi-R-J model. (d) $\delta_{2}$-score of Omi-R$\mathrm{J}$ model. The blue color block represents the period when the forecasting is valid at $95 \%$ confidence level. The red color block represents the result of $\delta_{1}<0.025$ or $\delta_{2}<0.025$, i.e. the forecasting period of failure. The blank area indicates that no earthquake event of or above cutoff magnitude has occurred in the forecasting period. And the slash area represents the time period that cannot participate in the calculation because of insufficient data. 


\section{Jinmeng Bi et al.}

be overestimated. To further compare forecast performances between the two models, we analyzed 10 sequences in the same forecasting periods of the two models. By comparison, the R-J model is more effective than the OmiR-J model with respect to having "too low" numbers of forecasted aftershocks, while the Omi-R-J model has significantly higher overall efficacy than the R-J model. Therefore, utilizing the R-J and Omi-R-J models by focusing on the bottom line thinking of "no more than" and "no less than" the corresponding forecasting earthquake number respectively may present practical value to post-earthquake relief in North China. Detailed evaluations of the efficacy for each earthquake sequence are given in Tables 2 and 3.

\begin{tabular}{|c|c|c|c|c|c|c|c|c|c|}
\hline \multirow{2}{*}{ Code } & \multirow{2}{*}{$\begin{array}{l}\text { Period } \\
\text { after the } \\
\text { mainshock }\end{array}$} & \multirow{2}{*}{$\begin{array}{l}\text { Forecasting } \\
\text { Magnitude }\end{array}$} & \multirow{2}{*}{$\begin{array}{l}\text { Number of } \\
\text { time-steps }\end{array}$} & \multicolumn{2}{|c|}{$\delta_{1}$-Score } & \multicolumn{2}{|c|}{$\delta_{2}$-Score } & \multicolumn{2}{|c|}{$\delta_{1}+\delta_{2}$ Score } \\
\hline & & & & $\delta_{1}<0.025$ & Ratio & $\delta_{2}<0.025$ & Ratio & $\begin{array}{c}\text { Failure } \\
\text { frequency }\end{array}$ & Ratio \\
\hline A & $0.05-5.00$ & 1.5 & 100 & 0 & 0 & 77 & $77.0 \%$ & 77 & $77.0 \%$ \\
\hline $\mathrm{B} \# *$ & $2.80-5.00$ & 1.5 & 45 & 0 & 0 & 0 & 0 & 0 & 0 \\
\hline $\mathrm{C \#}$ & $0.05-5.00$ & 4.0 & 92 & 0 & 0 & 43 & $46.7 \%$ & 43 & $46.7 \%$ \\
\hline $\mathrm{D}^{*}$ & $0.90-5.00$ & 4.0 & 92 & 6 & $6.5 \%$ & 81 & $88.0 \%$ & 87 & $94.5 \%$ \\
\hline E\# & $0.05-5.00$ & 1.5 & 94 & 0 & 0 & 27 & $28.7 \%$ & 27 & $28.7 \%$ \\
\hline $\mathrm{F} \# *$ & $1.65-5.00$ & 1.5 & 57 & 0 & 0 & 0 & 0 & 0 & 0 \\
\hline G & $0.05-5.00$ & 2.0 & 100 & 0 & 0 & 27 & $27.0 \%$ & 27 & $27.0 \%$ \\
\hline $\mathrm{H}$ & $0.05-5.00$ & 2.0 & 100 & 0 & 0 & 12 & $12.0 \%$ & 12 & $12.0 \%$ \\
\hline$I^{*}$ & $1.45-5.00$ & 3.0 & 82 & 0 & 0 & 29 & $35.4 \%$ & 29 & $35.4 \%$ \\
\hline $\mathrm{K} \# *$ & $0.10-5.00$ & 2.0 & 88 & 0 & 0 & 17 & $19.3 \%$ & 17 & $19.3 \%$ \\
\hline L\# & $0.65-5.00$ & 2.0 & 94 & 7 & $7.2 \%$ & 0 & 0 & 7 & $7.2 \%$ \\
\hline $\mathrm{M} \#^{*}$ & $1.00-5.00$ & 2.0 & 41 & 0 & 0 & 16 & $39.0 \%$ & 16 & $39.0 \%$ \\
\hline $\mathrm{N}^{*}$ & $2.80-5.00$ & 1.5 & 45 & 0 & 0 & 0 & 0 & 0 & 0 \\
\hline $\mathrm{O}$ & $0.05-5.00$ & 2.5 & 100 & 0 & 0 & 12 & $12.0 \%$ & 12 & $12.0 \%$ \\
\hline $\mathrm{Q} \#^{*}$ & $1.50-5.00$ & 2.5 & 49 & 0 & 0 & 3 & $6.1 \%$ & 3 & $6.1 \%$ \\
\hline S\# & $0.05-5.00$ & 1.5 & 38 & 0 & 0 & 0 & 0 & 0 & 0 \\
\hline $\mathrm{T} \#$ & $0.05-5.00$ & 1.5 & 78 & 9 & $11.5 \%$ & 7 & $9.0 \%$ & 16 & $20.5 \%$ \\
\hline U\# & $0.05-5.00$ & 1.5 & 88 & 1 & $1.1 \%$ & 5 & $5.7 \%$ & 6 & $6.8 \%$ \\
\hline $\mathrm{W} \#$ * & $1.80-5.00$ & 1.5 & 57 & 0 & 0 & 2 & $3.5 \%$ & 2 & $3.5 \%$ \\
\hline
\end{tabular}

* forecasting slip periods with no earthquakes occurrence.

\# which do not start from 0.05 day.

Table 2. N-test of short-term aftershock occurrence rate forecasted by R-J model

To further explore contributing factors for forecasting failures, we analyzed changes in the seismic network's monitoring capacity before and after 2008. The average failure rate of the R-J model turned from $27.0 \%$ before 2008 to $7.7 \%$ after, while that of the Omi-R-J model turned from $13.3 \%$ before 2008 to $8.9 \%$ after. We conducted fitting to better show the relationship between occurrence time and failure rate (Figure 8). As Figure 8 shows, with increased monitoring capacity over time, both models have witnessed improved forecasting capacity, which is more pronounced for the R-J model than the Omi-R-J model, also indicating smaller impact of the incomplete records of early aftershocks on the latter. Similar conclusions were made by Jiang et al. [2018] by randomly “deleting” small magnitudes. Thus, at the early stage after the mainshock when numerous aftershocks are unobserved due to dense overlapping of seismic waves, the Omi-R-J model has more practical usefulness. The development of monitoring technologies for improved monitoring capacity may be a key factor to raising aftershock forecasting efficacy. 
Forecasting strategy of early aftershocks

\begin{tabular}{|c|c|c|c|c|c|c|c|c|c|}
\hline \multirow{2}{*}{ Code } & \multirow{2}{*}{$\begin{array}{l}\text { Period } \\
\text { after the } \\
\text { mainshock }\end{array}$} & \multirow{2}{*}{$\begin{array}{l}\text { Forecasting } \\
\text { Magnitude }\end{array}$} & \multirow{2}{*}{$\begin{array}{l}\text { Number of } \\
\text { time-steps }\end{array}$} & \multicolumn{2}{|c|}{$\delta_{1}$-Score } & \multicolumn{2}{|c|}{$\delta_{2}$-Score } & \multicolumn{2}{|c|}{$\delta_{1}+\delta_{2}$ Score } \\
\hline & & & & $\delta_{1}<0.025$ & Ratio & $\delta_{2}<0.025$ & Ratio & $\begin{array}{l}\text { Failure } \\
\text { frequency }\end{array}$ & Ratio \\
\hline A & $0.05-5.00$ & 1.5 & 100 & 13 & $13.0 \%$ & 2 & $2.0 \%$ & 15 & $15.0 \%$ \\
\hline $\mathrm{B}^{\#^{* *}}$ & $0.10-5.00$ & 1.5 & 99 & 2 & $2.0 \%$ & 19 & $19.2 \%$ & 21 & $21.2 \%$ \\
\hline $\mathrm{C}^{\#}$ & $0.05-5.00$ & 4.0 & 92 & 1 & $1.1 \%$ & 0 & 0 & 1 & $1.1 \%$ \\
\hline $\mathrm{D}^{*}$ & $0.05-5.00$ & 4.0 & 100 & 13 & $13.0 \%$ & 64 & $64.0 \%$ & 77 & $77.0 \%$ \\
\hline$E^{\#}$ & $0.05-5.00$ & 1.5 & 94 & 0 & 0 & 0 & 0 & 0 & 0 \\
\hline $\mathrm{F}^{\#^{* *}}$ & $0.05-5.00$ & 1.5 & 81 & 18 & $22.2 \%$ & 0 & 0 & 18 & $22.2 \%$ \\
\hline G & $0.05-5.00$ & 2.0 & 100 & 4 & $4.0 \%$ & 0 & 0 & 4 & $4.0 \%$ \\
\hline $\mathrm{H}$ & $0.05-5.00$ & 2.0 & 100 & 10 & $10.0 \%$ & 0 & 0 & 10 & $10.0 \%$ \\
\hline$I^{*}$ & $0.05-5.00$ & 3.0 & 100 & 13 & $13.0 \%$ & 0 & 0 & 13 & $13.0 \%$ \\
\hline $\mathrm{J}^{\#^{*}}$ & $0.05-5.00$ & 3.0 & 89 & 13 & $14.6 \%$ & 0 & 0 & 13 & $14.6 \%$ \\
\hline $\mathrm{K}^{\# *}$ & $0.05-5.00$ & 2.0 & 89 & 0 & 0 & 10 & $11.3 \%$ & 10 & $11.3 \%$ \\
\hline $\mathrm{L}^{\#}$ & $0.05-5.00$ & 2.0 & 97 & 10 & $10.3 \%$ & 7 & $7.2 \%$ & 17 & $17.5 \%$ \\
\hline $\mathrm{M}^{\#^{* *}}$ & $0.05-5.00$ & 2.0 & 51 & 0 & 0 & 0 & 0 & 0 & 0 \\
\hline $\mathrm{N}^{*}$ & $0.15-5.00$ & 1.5 & 98 & 3 & $3.1 \%$ & 0 & 0 & 3 & $3.1 \%$ \\
\hline $\mathrm{O}$ & $0.05-5.00$ & 2.5 & 100 & 3 & $3.0 \%$ & 0 & 0 & 3 & $3.0 \%$ \\
\hline $\mathrm{P}^{\#^{*}}$ & $0.05-5.00$ & 1.5 & 58 & 2 & $3.4 \%$ & 5 & $8.6 \%$ & 7 & $12.0 \%$ \\
\hline $\mathrm{Q}^{\#^{*}}$ & $0.05-5.00$ & 2.5 & 68 & 0 & 0 & 1 & $1.5 \%$ & 1 & $1.5 \%$ \\
\hline $\mathrm{R}^{\# *}$ & $0.05-5.00$ & 1.5 & 94 & 2 & $2.1 \%$ & 0 & 0 & 2 & $2.1 \%$ \\
\hline $\mathrm{S}^{\#}$ & $0.05-5.00$ & 1.5 & 38 & 0 & 0 & 0 & 0 & 0 & 0 \\
\hline $\mathrm{T}^{\#}$ & $0.05-5.00$ & 1.5 & 78 & 17 & $21.8 \%$ & 0 & 0 & 17 & $21.8 \%$ \\
\hline $\mathrm{U}^{\#}$ & $0.05-5.00$ & 1.5 & 88 & 0 & 0 & 2 & $2.3 \%$ & 2 & $2.3 \%$ \\
\hline $\mathrm{V}^{\# *}$ & $0.05-5.00$ & 2.0 & 89 & 0 & 0 & 6 & $6.7 \%$ & 6 & $6.7 \%$ \\
\hline $\mathrm{W}^{\# *}$ & $0.05-5.00$ & 1.5 & 83 & 22 & $26.5 \%$ & 0 & 0 & 22 & $26.5 \%$ \\
\hline $\mathrm{X}^{\# *}$ & $0.05-5.00$ & 1.5 & 59 & 2 & $3.4 \%$ & 0 & 0 & 2 & $3.4 \%$ \\
\hline
\end{tabular}

Table 3. N-test of short-term aftershock occurrence rate forecasted by Omi-R-J model

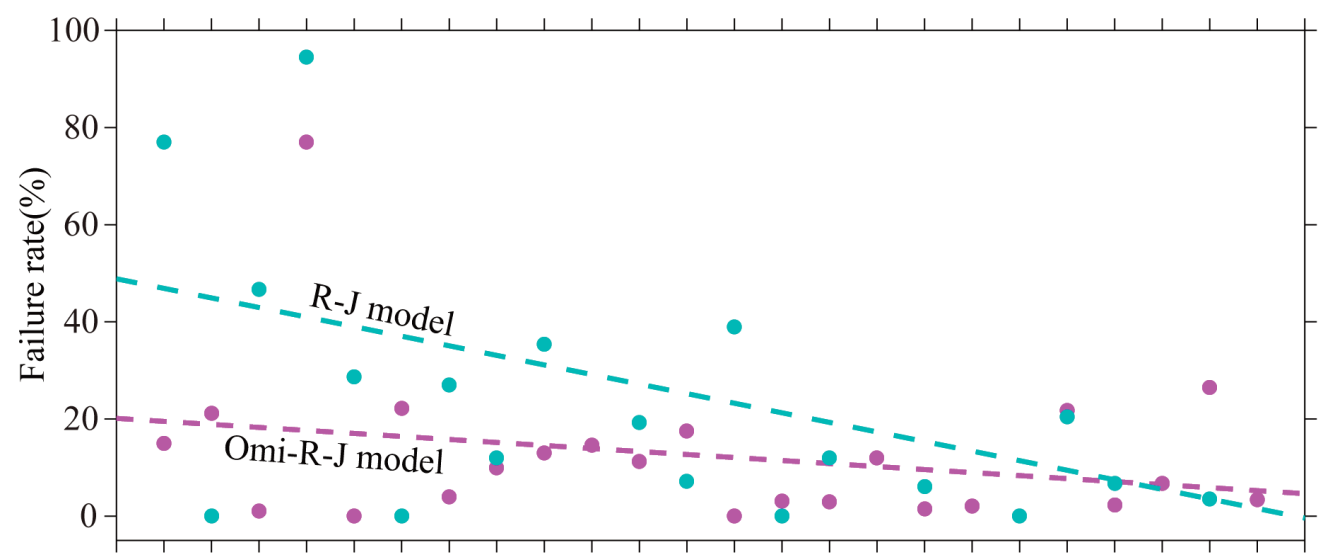

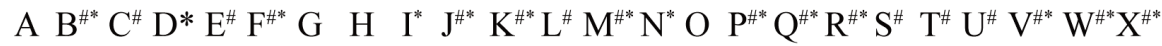

Original time of earthquake

Figure 8. The relationship between the forecasting failure rate and the onset time of the mainshock. The blue-green dots represents the failure of the R-J model for each earthquake sequence, the purple-red real point represents the failure of the Omi-R-J model for each earthquake sequence, and the blue-green and purple-red dashed lines represent the fitting curves of R-J model and Omi-R-J model respectively. 


\section{Jinmeng Bi et al.}

In addition, the T-test (Student's) method in CSEP was used to explore the relative merits of the two models. The T-test method can be expressed as the calculation of the average "information gain per earthquake" (IGPE) of model A relative to the model B in the confidence interval [Imoto, 2007]:

$$
\operatorname{IGPE}(A, B)=\frac{\ln L_{B}-\ln L_{A}}{N}
$$

where $N$ is the total number of "target earthquakes", and $\ln L_{A}$ and $\ln L_{B}$ are the likelihood functions of model $A$ and model $B$, respectively.

For calculations of the space grid, we adopted the same simplified method as Jiang et al. [2017], that is, directly using forecasting numbers of earthquakes in corresponding time windows. Based on the IGPE calculation method and the T-test, this study evaluated the forecasting efficacy of the Omi-R-J model relative to the R-J model for the sequences of 17 identical forecasting periods in North China according to their respective magnitudes. Test results at $95 \%$ confidence interval are shown in Figure 9. T-test results suggest that the Omi-R-J model significantly outperforms the R-J model for $88.2 \%(15 / 17)$ of the sequences.

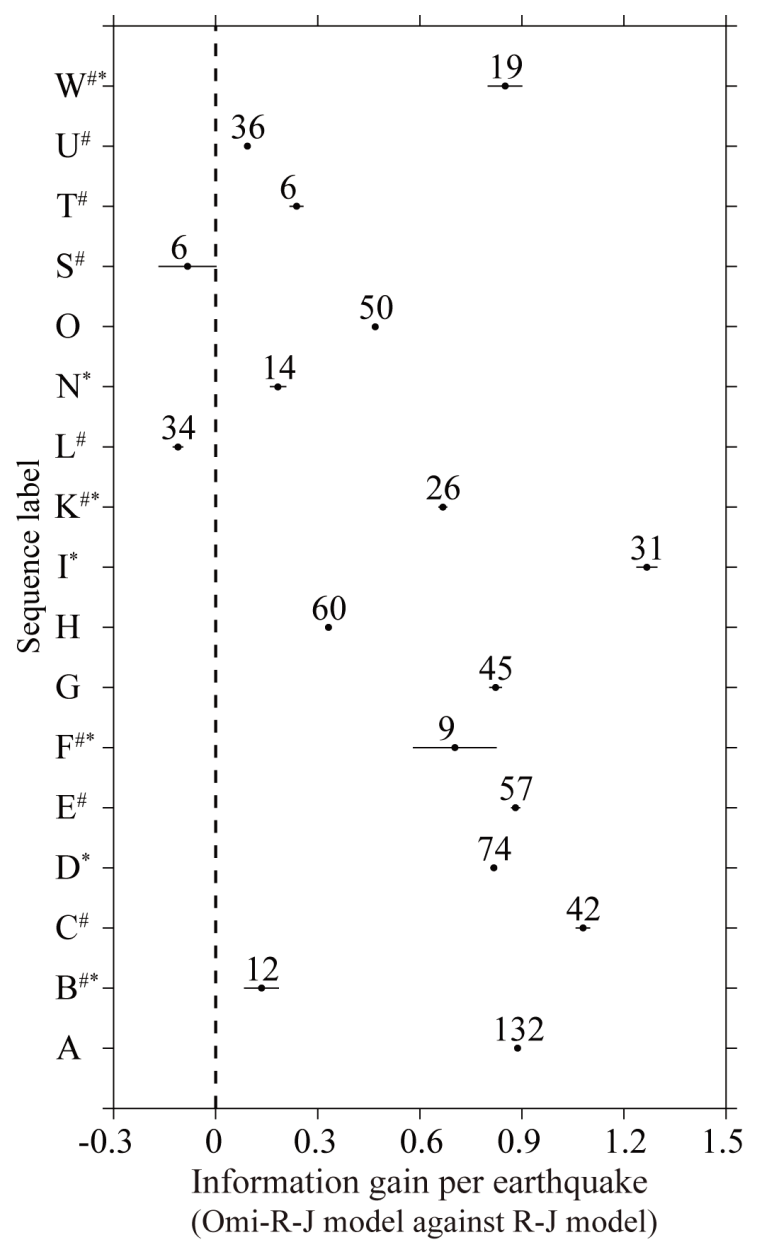

Figure 9. T-test results of the Omi-R-J model against the R-J model for aftershock forecasting of the earthquake sequence in North China, with different "target magnitudes". The black dots and horizontal lines represent the information gain per earthquake and the $95 \%$ confidence interval respectively, the number of observed earthquakes is shown above the T-test results. 


\section{Conclusion and Discussion}

To explore forecasting strategies for early aftershocks in North China, we have conducted a systematic comparative study of the widely used R-J model and the Omi-R-J model, which is capable of fully using large numbers of incomplete small-magnitude events in the early stage of the aftershock sequence, for 24 earthquake sequences in North China. We have arrived at the following conclusions by performing continuous sliding and fitting of multiple time windows, aftershock occurrence rate forecasting, and efficacy evaluation by the N-test and T-test:

1. Both the R-J model and Omi-R-J model prove rather effective for the early stage of sequences in the North China region, although the Omi-R-J model is generally better than R-J model, including the IGPE results given by T-test and the lower failure rate shown by N-test. Thus, it may be useful for post-disaster relief in North China to develop aftershock forecasting strategies that capitalize on the relative advantages of the R-J model and the Omi-R-J model in terms of relatively "low ratio of having 'too few' forecasted numbers of earthquakes” and "low total failure rate".

2. We analyzed changes in the seismic network's monitoring capacity before and after 2008 and we found that the average failure rate of the R-J model dropped from $27.0 \%$ before 2008 to $7.7 \%$ after; while that of the OmiR-J model dropped from $13.3 \%$ before 2008 to $8.9 \%$ after. This decline suggests considerable improvement in forecasting efficacy for earthquake sequences with the rapid growth of the seismic network following 2008, and that monitoring capacity is a key factor constraining forecasting efficacy. Considering that seismic network in China has improved significantly around 2008, especially the increase in the number of seismic stations and the quality of instruments, further enhancement of seismic monitoring capabilities in the future is still an important factor to improve the short-term aftershock forecasting capabilities in North China.

Immediate access to relatively stable model parameters is essential to improving forecasting capacity within a short time following strong earthquakes, while the missing aftershock sequences resulting from "submerged" small earthquake waveforms in the early stage may be one major factor affecting the stability of model parameters. In replenished early aftershock sequences datasets, tentative practices have been adopted to gain access to stable parameters after earthquakes, such as using "matched filtering” to pick up more repetitive aftershock events [Peng et al., 2006], a temporal point process with time-independent marks [Zhuang and Wang, 2016; Zhuang et al., 2017], etc. The results of this paper reveal the substantial impact of seismic monitoring capabilities on aftershock forecasting performance, therefore, the development of these new technologies provides another way to increase the potential of aftershock forecasting efficiency compared to investing in more seismic stations. The Omi-R-J model, which is formed by technical improvements based on the traditional R-J model, allows a large number of incomplete smallmagnitude earthquakes to participate in aftershock forecasting, further exerting the stability of model parameters fitting and the reliability of aftershock forecasting results. The application of these technologies has practical significance for formulating more scientific and reliable aftershock forecasting strategies in North China.

Acknowledgments. This study is supported by the Project of Tianjin Earthquake Agency (yb201901), the National Key R\&D Program (2018YFC1504601), the program of basic resources investigation of science and technology (2018FY100504) and the international partnership program of the Chinese Academy of Sciences (131551KYSB20160002). This study used the "National Unified Official Catalogue" provided by the China Earthquake Networks Center. We express our gratitude for Prof. Jiancang Zhuang of the Institute of Statistics and Mathematics (ISM) and Dr. Takahiro Omi of the Institute of Production Technology, Tokyo University, Japan, for their procedural and technical support. We also thank to anonymous reviewers whose comments and editing helped much to improve the paper.

\section{References}

Aki, K. (1965). Maximum likelihood estimate of $b$ in the formula $\log N=a-b M$ and its confidence limits. Bull. Earth. Re. Inst., Tokyo Unive., 43: 237-239.

Bi, J. M. and C. S. Jiang (2017). Evaluation on the forecasting effectiveness of short-term aftershock occurrence rate 


\section{Jinmeng Bi et al.}

and forecasting strategies at the junction of Shanxi, Hebei and Inner Mongolia. Prog. Geophys., 32: 8-17 (in Chinese).

Bi, J. M. and C. S. Jiang (2019). Distribution characteristics of earthquake sequence parameters in North China. Chinese J. Geophys. 62(11):4300-4312 (in Chinese).

Console, R., D. D. Jackson and Y. Y. Kagan (2010). Using the ETAS model for catalog declustering and seismic background assessment. Pure Appl. Geophys., 167: 819-830.

Enescu, B., J. Mori and M. Miyazawa (2007). Quantifying early aftershock activity of the 2004 mid-Niigata Prefecture earthquake ( $M_{\mathrm{W}}$ 6.6). J. Geophys. Res., 112: B04310.

Gardner, J. K. and L. Knopoff (1974). Is the sequence of earthquakes in Southern California with aftershocks removed, Poissonian? Bull. Seismol. Soc. Am., 64: 1363-1367.

Gerstenberger, M. C., S. Wiemer., L. M. Jones and P. A. Reasenberg (2005). Real-time forecasts of tomorrow's earthquakes in California. Nature, 435: 328-331.

Gutenberg, R. and C. F. Richter (1944). Frequency of earthquakes in California. Bull. Seismol. Soc. Am., 34: 185-188.

Han, P., K. Hattori, J. C. Zhuang, C. H. Chen, J. Y. Liu and S. Yoshida (2017). Evaluation of ULE seismo-magnetic phenomena in Kakioka, Japan by using Molchan's error diagram. Geophys. J. Int., 208: 482-490.

Helmstetter, A., Y. Y. Kagan and D. D. Jackson (2006). Comparison of short-term and long-term earthquake forecast models for southern California. Bull. Seismol. Soc. Am., 96: 90-106.

Huang, Q. (2006). Search for reliable precursors: A case study of the seismic quiescence of the 2000 western Tottori prefecture earthquake. J. Geophys. Res., 111: B04301.

Imoto, M. (2007). Information gain of a model based on multidisciplinary observations with correlations. J. Geophys. Res., 112: B05306.

Iwata, T. (2008). Low detection capability of global earthquakes after the occurrence of large earthquakes: Investigation of the Harvard CMT catalogue. Geophys. J. Int., 174: 849-856.

Japan Meteorological Agency (JMA) (2009). The Iwate-Miyagi Nairiku Earthquake in 2008. Rep. Coord. Comm. Earth. Predict., 81: 101-131.

Jiang, C. S. and Z. L. Wu (2011). Intermediate-term medium-range Accelerating Moment Release (AMR) priori to the 2010 Yushu $M_{\mathrm{S}} 7.1$ earthquake. Chinese J. Geophys., 54: 1501-1510 (in Chinese).

Jiang, C. S., Z. L. Wu, F. L. Yin, L. J. Guo, J. M. Bi and Y. W. Wang (2015). Stability of early estimation sequence parameters for continuous forecast of the aftershock rate: A case study of the 2014 Ludian, Yunnan $M_{\mathrm{S}} 6.5$ earthquake. Chinese J. Geophys., 58: 4163-4173 (in Chinese).

Jiang, C. S., J. C. Zhuang, Z. L. Wu and J. M. Bi (2017). Application and comparison of two short-term probabilistic forecasting models for the 2017 Jiuzhaigou, Sichuan, $M_{\mathrm{S}} 7.0$ earthquake. Chinese J. Geophys., 60: 4132-4144 (in Chinese).

Jiang, C. S., J. M. Bi, F. C. Wang, Y. G. Kui and F. Long (2018). Application of the Omi-R-J method for forecast of early aftershocks to the 2017 Jiuzhaigou, Sichuan, $M_{\mathrm{S}} 7.0$ earthquake. Chinese J. Geophys., 61: 2099-2110 (in Chinese).

Kagan, Y. Y. and D. D. Jackson (1995). New seismic gap hypothesis: Five years after. J. Geophys. Res., 100: 39343959.

Marzocchi, W. and A. M. Lombardi (2009). Real-time forecasting following a damaging earthquake. Geophys. Res. Lett., 36: L21302.

Nanjo, K. Z., H. Tsuruoka, S. Yokoi, Y. Ogata, G. Falcone, N. Hirata, Y. Ishigaki, T. H. Jordan, K. Kasahara, K. Obara, D. Schorlemmer, K. Shiomi and J. Zhuang (2012). Predictability study on the aftershock sequence following the 2011 Tohoku-Oki, Japan, earthquake: First results. Geophys. J. Int., 191: 653-658.

Omori, F. (1894). On aftershocks of earthquakes, Journal of the College of Science. Imperial University of Tokyo, 7: 11-200.

Ogata, Y. (1983). Estimation of the parameters in the modified Omori Formula for aftershock frequencies by the maximum likelihood procedure. J. Phys. Earth., 31: 115-124.

Ogata, Y. and K. Katsura (1993). Analysis of temporal and spatial heterogeneity of magnitude frequency distribution inferred from earthquake catalogues. Geophys. Res. Lett., 113: 727-738.

Ogata, Y. and K. Katsura (2006). Immediate and updated forecasting of aftershock hazard. Geophys. Res. Lett., 33: L10305.

Ogata, Y., K. Katsura, G. Falcone, K. Nanjo and J. C. Zhuang (2013). Comprehensive and topical evaluations of 
earthquake forecasts in terms of number, time, space, and magnitude. Bull. Seismol. Soc. Am., 103: 92-1708.

Ogata, Y., K. Katsura, H. Tsuruoka and N. Hirata (2018). Exploring magnitude forecasting of the next earthquake. Seismol. Res. Lett., 89: 1298-1304.

Omi, T., Y. Ogata, Y. Hirata and K. Aihara (2013). Forecasting large aftershocks within one day after the main shock. Sci. Rep., 3: 2218.

Omi, T., Y. Ogata, Y. Hirata and K. Aihara (2015). Intermediate-term forecasting of aftershocks from an early aftershock sequence: Bayesian and ensemble forecasting approaches. J. Geophys. Res., 120: 2561-2578.

Omi, T., Y. Ogata, K. Shiomi, B. Enescu, K. Sawazaki and K. Aihara (2016). Automatic aftershock forecasting: A test using real-time seismicity data in Japan. Bull. Seismol. Soc. Am., 106: 2450-2458.

Peng, Z., J. Vidale and H. Houston (2006). Anomalous early aftershock decay rate of the $2004 M_{\mathrm{W}} 6.0$ Parkfield, California, earthquake. Geophys. Res. Lett., 33: L17307.

Reasenberg, P. A. and L. M. Jones (1989). Earthquake hazard after a main shock in California. Science, 243: 1173-1176.

Schorlemmer, D., M. C. Gerstenberger, S. Wiemer, D. D. Jackson and D. A. Rhoades (2007). Earthquake likelihood model testing. Seismol. Res. Lett., 78: 17-29.

Schorlemmer, D., M. J. Werner, W. Marzocchi, T. H. Jordan, Y. Ogata, D. D. Jackson, S. Mak, D. A. Rhoades, M. C. Gerstenberger, N. Hirata, M. Liukis, P. J. Maechling, A. Strader, M. Taroni, S. Wiemer, J. D. Zechar and J. C. Zhuang (2018). The Collaboratory for the Study of Earthquake Predictability: Achievements and Priorities. Seismol. Res. Lett., 89: 1305-1313.

Shi, Y. and B. A. Bolt (1982). The standard error of the magnitude frequency $b$-value. Bull. Seismol. Soc. Am., 72 : 1677-1687.

Taroni, M., W. Marzocchi, D. Schorlemmer, M. J. Werner, S. Wiemer, J. D. Zechar, L. Heiniger, and F. Euchner (2018). Prospective CSEP evaluation of 1-day, 3-month, and 5-year earthquake forecasts for Italy. Seismol. Res. Lett., 89: $1251-1261$.

Utsu, T. (1961). A statistical study of on the occurrence of aftershocks. Geophy. Mag., 30: 521-605.

Utsu, T., Y. Ogata and R. S. Matsuura (1995). The Centenary of the Omori formula for a decay law of aftershock activity. J. Phys. Earth., 43: 1-33.

Woessner, J., S. Hainzl, M. J. Marzocchi, A. M. Lombardi, F. Catalli, B. Enescu, M. Cocco, M. C. Gerstenberger and S. Wiemer (2011). A retrospective comparative forecast test on the 1992 Landers sequence. J. Geophys. Res., 116: B05305.

Zechar, J. D. (2010). Evaluating earthquake forecasts and earthquake forecasts: A guide for students and new researchers, in: Community Online Resource for Statistical Seismicity Analysis, https://doi:10.5078/corssa77337879. Available at http://www.corssa.org. Accessed 28 Apr 2019.

Zhuang, J., D. Harte, M. J. Werner, S. Hainzl, D. Harte and S. Y. Zhou (2012). Basic models of seismicity: Temporal models, in: Community Online Resource for Statistical Seismicity Analysis, doi:10.5078/corssa-79905851. Available at http://www.corssa.org. Accessed 28 Apr 2019.

Zhuang, J. and T. Wang (2016). Correcting biases in the estimates of earthquake clustering parameters caused by shortterm missing of aftershocks. Japan Geoscience Union Meeting 2016, Makuhari, Chiba, Japan, 22-26 May 2016.

Zhuang, J., Y. Ogata and T. Wang (2017). Data completeness of the Kumamoto earthquake sequence in the JMA catalog and its influence on the estimation of the ETAS parameters. Earth, Planets and Space, 69: 36.

*CORRESPONDING AUTHOR: Changsheng JIANG,

Institute of Geophysics,

China Earthquake Administration,

Beijing, China,

e-mail: jiangcs@cea-igp.ac.cn

๑) 2020 the Istituto Nazionale di Geofisica e Vulcanologia.

All rights reserved 